\title{
Traqueostomia como alternativa à neoplasia traqueal em equino - relato de caso
}

Lara Antoniassi Del Rio", Diogo Augusto Freitas Ribeiro de Souza, Leandro Ramos Silveira Cardenas, Murilo Takeda, Nataly Any da Cunha Rafagnin, Robson Diego Maia nunes, Plinio Novaes Cordovil, Bruno Fornitano Cholfe, Guilherme Gonçalves Fabretti Santos, Igor Augusto Andreta Paiola, João morelli Junior, Suellen Miguez González

Centro Universitário de Rio Preto (UNIRP), São José do Rio Preto, SP, Brasil

*Autor correspondente

e-mail: laraantoniassi.vet@gmail.com

\section{Resumo}

Uma égua, Quarto de Milha, com 22 anos de idade e pesando $420 \mathrm{~kg}$, foi encaminhada ao Hospital Veterinário Dr. Halim Atique com queixa de dificuldade respiratória, emagrecimento e apatia há um ano. O proprietário relatou que anteriormente o animal recebeu tratamento com agentes broncodilatarores, havendo melhora momentânea do quadro seguida de piora acentuada. Ao exame físico inicial, observou-se mucosas normocoradas, frequência cardíaca de 44 bpm, frequência respiratória de 48 mpm acompanhada de ortopnéia, mas sem alterações em auscultação pulmonar, temperatura corporal de 37, 6ํㅡ e motilidade intestinal adequada. Posteriormente, o animal foi encaminhado à endoscopia, na qual notou-se presença de uma massa de ampla extensão na entrada da traqueia, da qual coletou-se fragmento para exame histopatológico. Ao exame histopatológico, tal massa se tratava de lesão pré-neoplasica de carcinoma associado a processo inflamatório pio granulomatoso. Adicionalmente, por se tratar de neoplasia, foi realizado exame radiológico em região pulmonar em busca de possível metástase, no entanto, nenhuma alteração condizente com metástase foi encontrada. Diante do quadro do animal, institui-se tratamento préoperatório à base de corticoide (dexametasona, intravenosa, duas vezes ao dia) e terapia antimicrobiana (trimetoprima em associação com sulfadimetoxina sódica, via oral, duas vezes ao dia). Após uma semana de tratamento, notou-se acentuada melhora clínica na respiração do animal e, por procedimento de endoscopia, notou-se leve regressão na massa. 0 paciente foi encaminhado à traqueostomia em busca de melhora na qualidade de vida do mesmo. Para tal procedimento, o animal foi sedado com detomidina, mantendo o mesmo em posição quadrupedal. Após tricotomia e antissepsia adequada, foi realizada a anestesia local da região cirúrgica e o procedimento, então, foi iniciado e executado no terço médio da traqueia. Após o procedimento cirúrgico, o animal permaneceu em terapia antimicrobiana por mais uma semana e recebeu também terapia analgésica. Concomitantemente, institui-se a limpeza da ferida cirúrgica duas vezes ao dia 
com solução à base de clorexidine alcóolico. Após cerca de dez dias, o animal recebeu alta e retornou à propriedade.

Palavras-chave: Carcinoma. Dificuldade respirátoria. Traqueostomia. 